\title{
The Inflammatory Marker hsCRP as a Predictor of Increased Insulin Resistance in Type 2 Diabetics without Atherosclerotic Manifestations
}

\begin{abstract}
ELENA-DANIELA GRIGORESCU ${ }^{1}$, VICTORITA SORODOC ${ }^{1,2 *}$, MARIANA FLORIA ${ }^{1,3}$, ECATERINA ANISIE ${ }^{4}$, ALINA DELIA POPA ${ }^{1,5}$, ALINA ONOFRIESCU ${ }^{1,5}$, ALEXANDR CEASOVSCHIH ${ }^{1,2}$, LAURENTIU SORODOC ${ }^{1,2}$

${ }^{1}$ Grigore T. Popa University of Medicine and Pharmacy, Faculty of Medicine, 16 University Str., 700115, Iasi, Romania

${ }^{2} 2^{\text {nd }}$ Medical Clinic, St. Spiridon Clinical County Emergency Hospital, 1 Independentei Blvd.,700111, Iasi, Romania

${ }^{3} 3^{\text {rd }}$ Medical Clinic, St. Spiridon Clinical County Emergency Hospital, 1 Independentei Blvd.,700111, Iasi, Romania

${ }^{4}$ Imunology, St. Spiridon Clinical County Emergency Hospital, 1 Independentei Blvd.,700111, Iasi, Romania

${ }^{5}$ Clinical Center of Diabetes, Nutrition and Metabolic Diseases Clinic, St. Spiridon Clinical County Emergency Hospital, 1 Independentei Blvd.,700111, lasi, Romania

Low-grade inflammation is not only a specific feature in type 2 diabetes mellitus, but also a contributor to cardiovascular risk. Together with insulin resistance as the main characteristic of type 2 diabetes mellitus, subclinical imflammation maintains a vicious cycle of health-damaging processes. Our study assessed the inflammatory marker hsCRP in relation to the metabolic profiles of type 2 diabetic patients without clinical atherosclerotic manifestations. The results confirmed the hypothesized connection, which should be taken into consideration when designing and recommending diabetes care plans.
\end{abstract}

Keywords: hsCRP, insulin resistance, subclinical inflammation, type 2 diabetes mellitus

The prevalence of diabetes mellitus has reached a staggering 425 million patients in 2017 and up to $50 \%$ more people are expected to be diagnosed by 2045 [1]. It is well known that diabetics are exposed to cardiovascular disease and higher related mortality. Hypertension, dyslipidaemia and obesity increase the level of risk already generated by subclinical inflammation [2]. Research has provided ample evidence of how inflammation may trigger insulin resistance, and it has thus justified the reconsidering of T2D as an inflammatory disorder [3]. Also, both microand macrovascular complications associated with diabetes seem to be driven by inflammation. A vicious cycle emerges whenever chronic insulin resistance and low-grade inflammation trigger and aggravate each other [4]. This is a noteworthy consideration in preventative clinical practice, given that insulin resistance is known to interfere in incipent atherosclerosis estimated by intimmedia thickness even in prediabetic patients [5].

Although subtle, a chronic inflammatory state can be detected by measuring the level of certain proinflammatory cytokines (TNF- $\alpha$, IL- 6 , IL-1 etc.). The best known marker for these cytokines is hsCRP, a calcium dependent ligandbinding plasma protein from the pentraxin family. It is mainly synthesized in the liver as a reaction to proinflammatory cytokines and is mediated by IL- 6 and TNF- $\alpha$. Alternatively, hsCRP can be produced by SMCs lymphocytes and monocytes in local atherosclerotic lesions [6]. This reveals a researchable connection between inflammation by means of a measurable sensitive marker such as CRP, on one hand, and the onset and development of atherosclerotic disease, on the other [7].

Atherosclerosis, an inflammatory process itself, is responsible for macrovascular complications even in the absence of perceived signs and symptoms. Among the CRP-induced damage in atherosclerosis are: vascular wall damage, activation of complement cascade, prothrombotic state, RAAS (Renin Angiotensin Aldosterone
System) activation, plaque remodeling, oxidative stress and endothelial dysfunction [8].

Apart from its usefulness in assessing inflammation, increased CRP levels can also be strong predictors or indicators of cardiovascular risk and disease (Ml, stroke, peripheral arterial disease etc.) [9]. Studies have shown that asymptomatic individuals, too, may present high levels of CRP, which provides an interesting avenue to beneficial research and applications.

The aim of this cross-sectional study was to analyze the associations between low-grade inflammation and the metabolic profile of type 2 diabetic patients who did not present any clinical signs of atherosclerotic disease. This is part of a larger doctoral research project which also addresses cardiovascular implications and offers a prospective view with practical recommendations and therapeutic benefits.

\section{Experimental part}

\section{Material and methods}

The overall research project includes a cohort of outpatients treated at a Clinical Centre of Diabetes, Nutrition and Metabolic Diseases from June 2016 until February 2018. These are all patients with unsatisfactory glycemic control, for which the diabetologist recommended adjusting the therapy with non-insulin drugs, in accordance with national protocols.

For the purposes of this study, we selected 120 subjects based on the following inclusion criteria: written informed consent, age between 30-75 and type 2 diabetes unsuccessfully kept under control by metformin and/or sulphonylurea therapy. The exclusion criteria were: smoking, atherosclerotic cardiovascular disease (myocardial infarction, angina, coronary revascularization, electrocardiogram findings of ischemia, stroke, transient ischemic attack, peripheral arterial disease), history of severe liver or kidney disease, history of acute pancreatitis, 
major chronic infections, pregnancy or intention to procreate, lack of consent.

The first step was to obtain informed consent in writing and collect demographic and medical information by means of a questionnaire (including about comorbidities, treatment and history of diabetes). The patients were viewed clinically, measurements were taken (weight, height, waist circumference) and their BMls were calculated.

Blood was sampled after $8 \mathrm{~h}$ of overnight fasting in order to profile their lipid and glycemic values, as well as assess kidney and liver function. Blood samples were taken immediately to be centrifuged at $3000 \mathrm{G}$ for $5 \mathrm{~min}$ so as to ensure the correct measurement of insulin and C-peptide. The serum was then stored at $-20^{\circ} \mathrm{C}$, and the levels of hsCRP, insulin and C-peptide were measured using chemiluminiscence techniques (IMMULITE 1000). HbA was measured by means of Ion-exchange high-performance liquid chromatography.

\section{Statistical analysis}

The data was collected, processed and analyzed in SPSS 17.0 for Windows (SPSS Inc., Chicago): descriptive statistics, t-testing, Spearman correlations, linear and logistic regression models (including area under the ROC curve) and statistical significance thresholds ( $p<0.05)$. For the assessment of insulin resistance, we employed validated formulae HOMA-IR = (glycemia a jeun in $\mathrm{mg} / \mathrm{dL}$ $x$ insulinemia a jeun in $\mu \mathrm{U} / \mathrm{mL}$ ) / 405 and HOMA C-peptide $=$ (glycemia à jeun in mg/dL /18 $\times$ C-peptide $\times 3.003) /$ $22.5[10]$.

\section{Results and discussions}

The demographic features of these 120 patients can be summarized as follows: $45 \%$ men, mean age $58.16 \pm 8.72$ (56.7\% of patients were aged between 50 and 65 years, $23.3 \%$ of patients were older than 65 years, and $20 \%$ of patients were younger than 50 years), mean history of type2 diabetes of $6.04 \pm 4.63$ years upon joining the study.

Their mean BMI and mean abdominal circumference were $32.75 \pm 5.65 \mathrm{~kg} / \mathrm{m}^{2}$ and $109.48 \pm 12.62 \mathrm{~cm}$, respectively, highlighting the fact that most were obese $(66.7 \%)$ or overweight $(29.2 \%)$, consistent with known association between obesity and type-2 diabetes. The patients' glycemic control, lipid profile, and uric acid are summarized in table 1.
With regard to known metabolic control targets in diabetics, the total cholesterol in $42.5 \%$ of our patients was above $200 \mathrm{~mL} / \mathrm{dL}$, and the LDL-cholesterol was within 70 $\mathrm{mL} / \mathrm{dL}$ in only $17.9 \%$ of cases. Similarly, only a third had levels of triglycerides below $150 \mathrm{mg} / \mathrm{dL}$.

The aforementioned formulae produced the indices of insulin resistance in table 2 . The only metabolic profile parameters which correlated significantly with insulin resistance were HDL-cholesterol with HOMA-IR $(r=-0.24$, $p=0.007)$, triglycerides with HOMA C-peptide $(r=0.19, p$ $=0.03)$ and uric acid with HOMA C-peptide $(r=0.28, p=$ 0.001 ). These results bear clinical relevance in themselves but also in light of diabetics' known predisposition to developing long term complications such as chronic kidney disease (CKD), in which case levels of HOMA-IR, uric acid and triglycerides tend to be higher or even predict CKD [11].

\section{Inflammation assessment}

The level of serum hsCRP has already been demonstrated as a predictor of cardiovascular events. Moreover, the higher the hsCRP, the higher the risk of such an event and the worse the prosnosis afterwards. This has lead to the proposal of a risk stratification chart according to which more than $3 \mathrm{mg} / \mathrm{L}$ of hsCRP is indicative of a high level of risk. The measurement of hsCRP is useful in both primary and secondary cardiovascular prevention $[12,13]$.

Robust evidence has been collected widely and reviewed thoroughly to reveal that hSCRP is a risk factor for diabetes but also for the onset of pre-diabetic manifestations, even if a causal relationship is difficult to confirm by cross-sectional research [14,15]. Furthermore, increased hSCRP has been associated with popular diets in western countries, proving the pro-inflammatory effects of certain foods and highlighting the role that diet may play in alleviating / preventing chronic disease versus promoting / aggravating it [16]. However, nutritional intervention is neither straightforward nor ethically sound in every case [17].

Such insights from the literature justify our interest in the hsCRP levels of our patients. In their case, the median value of hsCRP was $5.40 \mathrm{mg} / \mathrm{L}$ (interquartile range 8.92), after the exclusion of 2 outliers whose levels were in excess of $50 \mathrm{mg} / \mathrm{L}$. Another 88 patients had more than $3 \mathrm{mg} / \mathrm{L}$ hsCRP, suggesting that $75 \%$ were at high risk of Table 1 cardiovascular events.

Table 1

METABOLIC PROFILE OF PATIENTS INCLUDED IN THE STUDY

\begin{tabular}{|l|c|c|c|c|c|c|}
\hline Parameters & $\begin{array}{c}\mathrm{HbA}_{\mathbf{l c}} \\
(\mathbf{\%})\end{array}$ & $\begin{array}{c}\text { Cholesterol } \\
(\mathbf{m g} / \mathbf{d L})\end{array}$ & $\begin{array}{c}\text { HDL } \\
\text { cholesterol } \\
(\mathbf{m g} / \mathbf{d L})\end{array}$ & $\begin{array}{c}\text { LDL } \\
\text { cholesterol } \\
(\mathbf{m g} / \mathbf{d L})\end{array}$ & $\begin{array}{c}\text { Triglycerides } \\
(\mathbf{m g} / \mathbf{d L})\end{array}$ & $\begin{array}{l}\text { Uric acid } \\
(\mathbf{m g} / \mathbf{d L})\end{array}$ \\
\hline Mean & 8.03 & 195.04 & 56.28 & 103.9 & 205.19 & 5.41 \\
\hline Median & 7.80 & 192.00 & 55.97 & 109 & 195.50 & 5.35 \\
\hline Std.Deviation & 0.95 & 47.59 & 15.09 & 40.68 & 93.4 & 1.35 \\
\hline Minimum & 7.00 & 92 & 29 & 15.2 & 60 & 1.1 \\
\hline Maximum & 11.30 & 342 & 102 & 217.0 & 436 & 8.9 \\
\hline
\end{tabular}

Table 2

PARAMETERS OF INSULIN RESISTANCE IN PATIENTS INCLUDED IN THE STUDY

\begin{tabular}{|c|c|c|c|c|c|c|}
\hline & Mean & Median & Std. deviation & Minim & Maxim & $\begin{array}{c}\text { Interquartile } \\
\text { range }\end{array}$ \\
\hline Glucose $(\mathrm{mg} / \mathrm{dL})$ & 171.60 & 167.00 & 43.25 & 100 & 310 & 46 \\
\hline Insulin $(\mu \mathrm{U} / \mathrm{Ml})$ & 14.31 & 13.60 & 8.90 & 2.00 & 51.40 & 10.32 \\
\hline C-Peptide $(\mathrm{ng} / \mathrm{mL})$ & 3.25 & 3.26 & 1.36 & 0.9 & 8.3 & 1.7 \\
\hline HOMA-IR & 6.08 & 5.59 & 4.00 & 0.59 & 22.24 & 5.33 \\
\hline HOMA C-peptide & 4.15 & 3.73 & 2.00 & 0.87 & 10.60 & 2.77 \\
\hline
\end{tabular}


With regard to the assessment of clinical inflammation, too, hsCRP was proven to be a predicting factor for some of the diagnosis criteria in metabolic syndrome (diabetes, obesity, dyslipidemia) [18]. In addition, increased values of this marker have been associated with type 2 diabetes more than with other types in the context of the immunologic profiling of diabetic patients. While adiposity markers correlated positively with hsCRP, they also correlated negatively with adiponectin as an antiinflammatory, protective marker [19-20].

The Kurskal-Wallis test and our analysis of differences between the mean values of relevant parameters in relation to the hSCRP risk threshold $(>3$ ) revealed statistical significance only for BMI (fig. 1) and abdominal circumference ( $p<0.01$ in both cases). None of the indices corresponding to the metabolic profile were signficantly influenced by elevated hsCRP.

The analysis of hsCRP results indicative of subclinical inflammation confirms the statistically significant relation with $\mathrm{BMI}(r=0.33, p<0.01)$ reported in the literature both at similar and higher rintenstity values [21]. In our study, a similar correlation was identified between hsCRP and the patients' abdominal circumference $(r=0.403, p<0.01)$. Furthermore, we found a positive correlation between hsCRP and uric acid, consistent with the mentioned adiposity-related markers $(r=0.196, p=0.033)$.

\section{hsCRP}

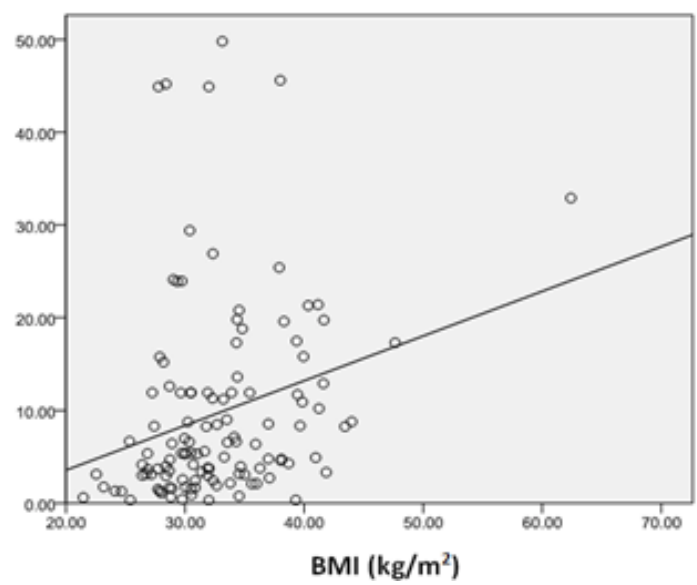

- Observed Fi ine for Total

Fig. 1. The correlation between BMI and hsCRP

As previously shown, only a very small percentage of the patients included in the study were of normal weight. Excessive abdominal adiposity is known to maintain subclinical inflammation, which in turn triggers insulin resistance,impaired glucose tolerance and diabetes itself. Further analysis by means of linear regression reinforced the idea that higher BMI values point to augmented seric levels of hsCRP (fig. 2) and, therefore, stronger inflammation $\left(R^{2}\right.$ Linear $\left.=0.069\right)$. Since $B M l$ is easy to measure, it can serve as a useful clue.

When hsCRP was assessed comparatively across patients BMI groups (fig. 2), significant differences in hsCRP means were found between normal weight versus overweight patients ( $1.6 \mathrm{mg} / \mathrm{L}$ vs. $9.01 \mathrm{mg} / \mathrm{L}, p=0.01)$, as well as between the normal weight versus the obsese groups ( $1.6 \mathrm{mg} / \mathrm{L}$ vs. $10.52 \mathrm{mg} / \mathrm{L}, p<0.01)$. However, hsCRP means did not differ significantly between overweight and obese patients $(p=0.48)$, which points to any weight in excess of $25 \mathrm{~kg} / \mathrm{m}^{2}$ as a risk factor for subclinical inflammation. A chain reaction is triggered as altered adipocytes send chemical stress signals and lead to elevated levels of free fatty acids. These activate serine

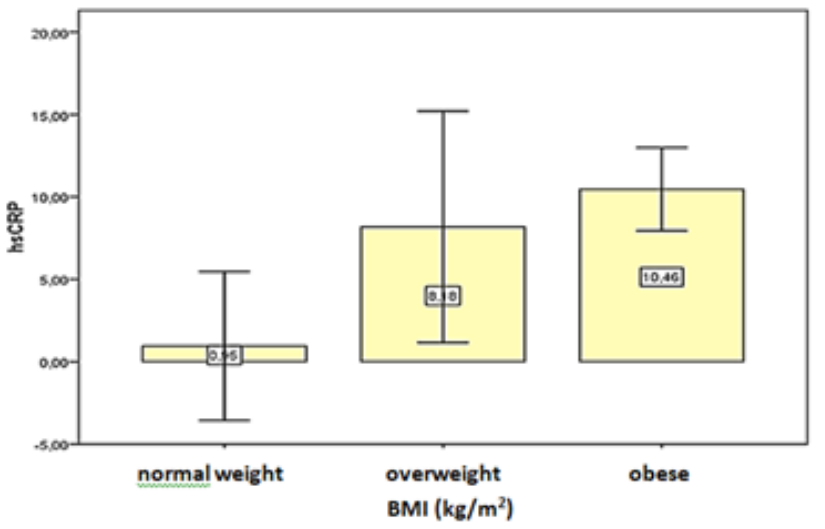

Fig. 2. The relationship between hsCRP and mean BMI

kinases enabling adipose tissues to produce TNF- $\alpha$ and IL6 , which triggers the synthesis of hsCRP in the liver [22].

Next, we analyzed HbAlc and its relationship with hsCRP. Generally used to refer to the patients' level of glycemic control, the $\mathrm{HbAlc}>7$ in all our patients is in fact an indication of glycemic imbalance similar to that reported in the literature. We also found a significant positive association between hsCRP and HbAlc $(r=0.18, p=0.042)$, though poorer than in other studies involving diabetics and non-diabetics [23]. The degree of glycemic imbalance did not seem to affect that of subclinical inflammation according to our data (table 3), unlike in other studies where the poorer the glycemic control, the higher the level of hSCRP [24].

Table 3

THE RELATIONSHIP BETWEEN MEAN hSCRP AND GLYCEMIC IMBALANCE

\begin{tabular}{|c|c|c|c|}
\hline hsCRP & $<7.5$ & $11.18 \pm 18.41$ & $\mathrm{p}=0.233$ \\
\cline { 2 - 3 } $\mathrm{mg} / 1$ & $7.5-8$ & $11.14 \pm 16.96$ & \\
\cline { 2 - 3 } & $>8$ & $11.18 \pm 10.75$ & \\
\hline
\end{tabular}

Assessment of the subclinical inflammation marker in connection with insulin resistence parameters (defined and measured as explained) is also noteworthy. Table 4 summarizes the significant direct correlation between the two. Furthermore, when grouping the patients based on insulin resistance grading established in the literature as HOMA-IR $<2,2-5,>5$, the ROC analysis identified highsensitive hsCRP as a predictor of increased insulin resistance: 64 of the 120 patients included in the study were graded $>5$ and had high levels of hsCRP.

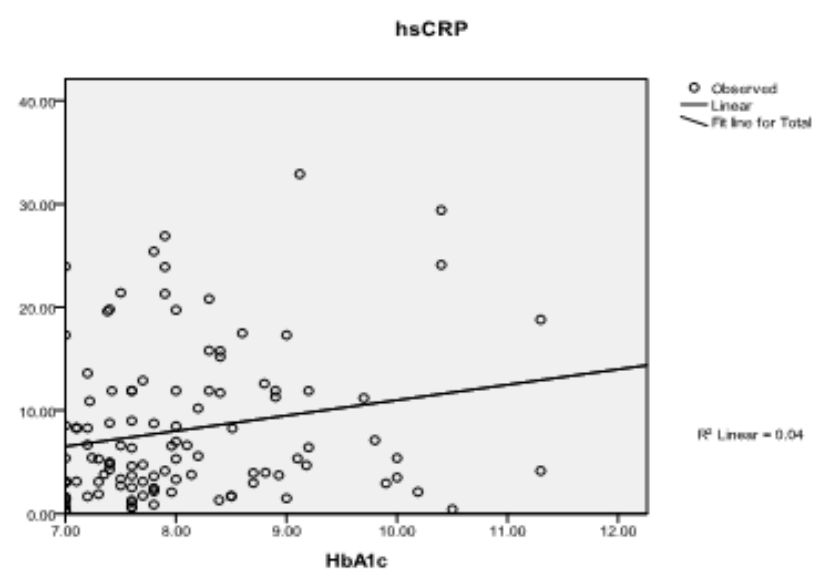

Fig. 3. The correlation between hsCRP and HbAlc 
Table 4

THE RELATIONSHIP BETWEEN INSULIN RESISTANCE AND INFLAMMATION MARKERS

\begin{tabular}{|c|c|c|c|c|c|}
\hline \multicolumn{2}{|c|}{$\begin{array}{c}\text { Spearman } \\
\text { correlations }\end{array}$} & insulin & C peptide & HOMA-IR & $\begin{array}{c}\text { HOMA-C } \\
\text { peptide }\end{array}$ \\
\hline hsCRP & $\mathrm{r}$ & 0.25 & 0.21 & 0.29 & 0.22 \\
& $\mathrm{p}$ & 0.005 & 0.02 & 0.001 & 0.01 \\
\hline
\end{tabular}

ROC Curve

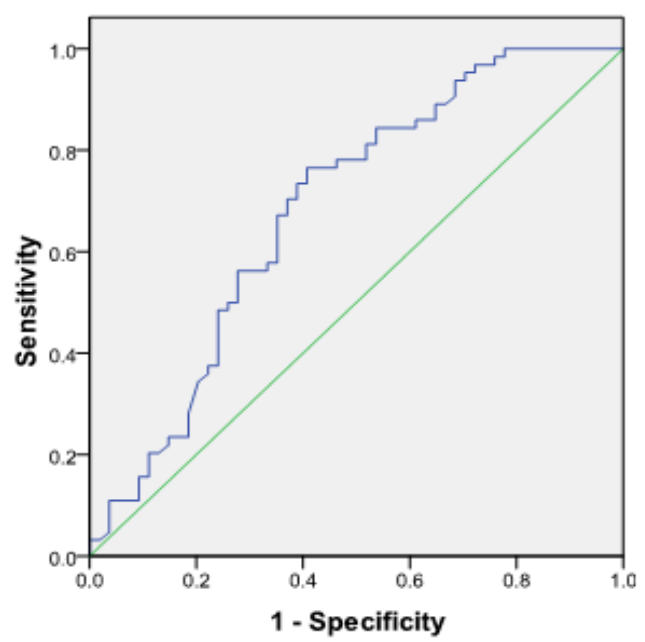

Fig. 4. The ROC curve for hSCRP as a predictor of increased insulin resistance

\section{Conclusions}

Subclinical inflammation and insulin resistance are key factors in the pathogenesis of diabetes and cardiovascular disease. Their presence and severity can be appraised by measuring hsCRP and HOMA-IR, respectively. Adiposityrelated indices are also easily determined and helpful in profiling patients' metabolic status.

Our study enrolling overweight/obese T2DM patients confirms that low-grade inflammation and glycemic imbalance are positively correlated, and that hSCRP may be used a predictor of hightened insulin resistance. These findings justify scientific and clinical interest in the assessment of inflammatory biomarkers, especially since our patients did not present signs of atherosclerosis. Subtle inflammatory chain reactions promote and aggravate atherosclerotic lesions, contributing to the high prevalence of macrovascular complications in diabetics.

\section{References}

1.***INTERNATIONAL DIABETES FEDERATION. IDF Diabetes Atlas, 8th edn. Brussels, Belgium, 2017, http://www.diabetesatlas.org 2.ELLULU, M., PATIMAH, I., KHAZA'Al, H., RAHMAT, A., ABED. Y., Archives of Medical Science, 4, 2017, p. 851-863.
3.HAMEED, I., MASOODI, S., MIR, S., NABI, M. et al, World J ournal of Diabetes, 6, no. 4, 2015, p. 598.

4.ZHENG, N., SHI, X., CHEN, X., LV, W., Laboratory Medicine, 46,no.3, 2015, p.214-220.

5.MIHAI, B., PETRIS, A., UNGUREANU, D., LACATUSU, C., Open Medicine, 10, no. 1, 2015, p. 14-24.

6.PAFFEN, E., DEMAAT, M., Cardiovascular Research, 71, no. 1, 2006, p. 30-39.

7.SHRIVASTAVA, A., SINGH, H., RAIZADA, A., SINGH, S., The Egyptian Heart J ournal, 67, no. 2, 2015, p. 89-97.

8.ADUKAUSKIENE, D., CIGINSKIENE, A., ADUKAUSKAITE, A., PENTIOKINIENE, D., SLAPIKAS, R., CEPONIENE, I., Medicina, 52, no. 1, 2016, p.1-10.

9.USLU, S., KEBAPCl, N., KARA, M., BAL, C., Experimental and Therapeutic Medicine, 4, no. 1, 2012, p. 113-120.

10.WALLACE, T.M., LEVY, J.C., MATTHEWS, D.R., Diabetes Care 27, 2004, p.1487-95.

11.MOTA, E., POPA, S., MOTA, M. et al., International Urology and Nephrology, 47, no. 11, 2015, p. 1831-1838.

12.RIDKER, P., J ournal of the American College of Cardiology, 67, no. 6, 2016, p. 712-723.

13.BAO, X., BORNE, Y., JOHNSON, L., MUHAMMAD, I., PERSSON, M., NIU, K., ENGSTROM, G., Cardiovascular Diabetology, 17:87, 2018.

14.BELLOU, V., BELBASIS, L., TZOULAKI, I., EVANGELOU, E., PLOS ONE, 13, no. 3, p.e0194127.

14. BELLOU, V., BELBASIS, L., TZOULAKI, I., EVANGELOU, E., PLOS ONE, 13, no. 3, p.e0194127.

15. BRAHIMAJ, A., LIGTHART, S., GHANBARI, M., IKRAM, M. et al., European Journal of Epidemiology, 32, no. 3, 2017, p. 217-226.

16. MAZIDI, M., SHIVAPPA, N., WIRTH, M., HEBERT, J., MIKHAILIDIS, D., KENGNE, A., BANACH, M. Atherosclerosis, 276, 2018, p. 23-27.

17. LACATUSU, C.M., CIJEVSCHI-PRELIPCEAN, C., MIHAI, C., MIHAI, B.M., Rev Rom Bioet 2014; 12: 44-55.

18. MENG, Y., FORD, E., LI, C., QUARSHIE, A., AL-MAHMOUD, A., GILES, W., GIBSSON, G., STRAYHORN, G. Clinical Chemistry, 53, no. 12, 2007, p. 2152-2159.

19. GOWDAIAH, P., NIRGUDE, D., HOSAMANI, P., International J ournal of Advances in Medicine, 3, no.3, 2016, p. 607-610.

20. ABU-FARHA, M., BEHBEHANI, K., ELKUM, N., Cardiovascular Diabetology, 13, no. 1, 2014, p. 76.

21. VINAGRE, I., SANCHEZ-QUESADA, J., SáNCHEZ-HERNáNDEZ, J., SANTOS, D. et al, Cardiovascular Diabetology, 13, no. 1, 2014, p. 34.

22. ROCHA, V., LIBBY, P. Nature Reviews Cardiology, 6, no. 6, 2009, p. 399-409.

23. ELIMAM, H., ABDULLA, A., TAHA, I., Diabetes \& Metabolic Syndrome: Clinical Research \& Reviews, 13, no. 1, 2019, p. 800-804. 24. POREBA, M., ROSTOFF, P., SINIARSKI, A. et al, Cardiovascular Diabetology, 17, no. 1, 2018.

$\overline{\text { Manuscript received } 8.10 .2018}$ 